\title{
Primary Health Care Research \& Development
}

VOLUME 12 ISSUE 2 APRIL 2011

\section{CONTENTS}

\section{Editorial}

81 Academic Primary Care: time to review and integrate

Ann Adams, Helen Lester, Sally Kendall and Ros Bryar

\section{Development}

83 Development and application of the Imperial College Obesity Strategy Assessment Framework for analysing local obesity strategies

Nik A.A. Tuah, Samrina Qureshi, Waljit S. Dhillo and Azeem Majeed

95 A service model for delivering care closer to home

Joanna Dodd, Charlotte Elizabeth Taylor, Paul Bunyan, Philippa Mary White, Siân Myra Thomas and Dominic Upton

\section{Research}

112 Factors influencing engagement of patients in a novel intervention for CFS/ME: a qualitative study Carolyn Chew-Graham, Joanna Brooks, Alison Wearden, Christopher Dowrick and Sarah Peters

123 The frequency distribution of presenting symptoms in children aged six months to six years to primary care Sara Whitburn, Céire Costelloe, Alan A. Montgomery, Niamh M. Redmond, Margaret Fletcher, Tim J. Peters and Alastair D. Hay

135 Investigation of the oral health needs for homeless people in specialist units in London, Cardiff, Glasgow and Birmingham Kirsty B. Hill and Debbie Rimington

145 Improving the utilization of health and nutrition services: experience from the Catholic Relief Services supported the Development Assistance Programme in Ghana

Mahama Saaka and Sylevester Galaa

157 The epidemiology of patellofemoral disorders in adulthood: a review of routine general practice morbidity recording Laurence Wood, Sara Muller and George Peat

165 The experiences and needs of people seeking palliative health care out-of-hours: a qualitative study Suzanne H. Richards, Rachel Winder, Clare Seamark, David Seamark, Sarah Avery, James Gilbert, Angela Barwick and John L. Campbell

\section{Short Report}

179 Sickness certification for mental health problems: an analysis of a general practice consultation database Christian D. Mallen, Gwenllian Wynne-Jones and Kate M. Dunn

\section{Networking}

183 The Society for Academic Primary Care: Position Statement April 2011 Joanne Reeve 


\section{PRIMARY HEALTH CARE RESEARCH \& DEVELOPMENT}

As primary health care continues to grow in importance in relation to the rest of health care provision, this journal provides a source of information on the growing body of knowledge concerning research and development issues in primary health care. This is the first journal aimed specifically at both researchers and practitioners in primary health care, thereby bridging the gap between the two areas. It provides a forum for the publication of international, interdisciplinary research and development in primary health care (PHC).

\section{Aims and Scope}

- to disseminate evidence, information and practice examples of PHC research and developmental activities

- to analyse and debate the meaning of evidence and ways in which practice in PHC may be developed to reflect best practice, including clinical audit, quality issues and cost-effectiveness

- to draw on and promote the use of the full range of research methods in PHC research

- to provide a forum for communication between practitioners, researchers, educators and policy-makers concerned with achieving PHC-led services worldwide

- to involve user-groups as well as PHC professionals, thus reflecting accepted views on involvement of consumers in research and policy development

- to reflect and explore the political context of health care development

- to include work concerned will all aspects of PHC including prevention, health promotion, public health, education, clinical effectiveness, organizational and management issues, quality issues and policy development

\section{Networking}

This section covers the work of research networks and other initiatives to promote collaboration or build capacity in primary care research. Articles can raise issues, inform or challenge, comment on current events, or seek collaborative partners. Articles of up to 1000 words will be subject to editorial review and published as quickly as space allows. Longer contributions will be subject to peer review, as are other papers submitted to the journal.

\section{Research}

Research papers (normally up to 5000 words) will be considered as those which do one or more of the following:

- Report on primary data, either quantitative or qualitative

- Offer a critical analysis of research method(s)

- Provide a critical and systematic overview of previous studies

- Provide new theoretical/conceptual insights into phenomena

- Critically inform the evidence base for practice

\section{Development}

Development papers (normally up to 5000 words) will be considered as those which do any one or more of the following:

- Report on a change in practice

- Demonstrate how evidence supports change

- Report on audit data or pilot study data

- Report on evaluation process

- Analyse policy which underpins change in practice

A full version of the Information for Authors text can be found at journals.cambridge.org/phc 


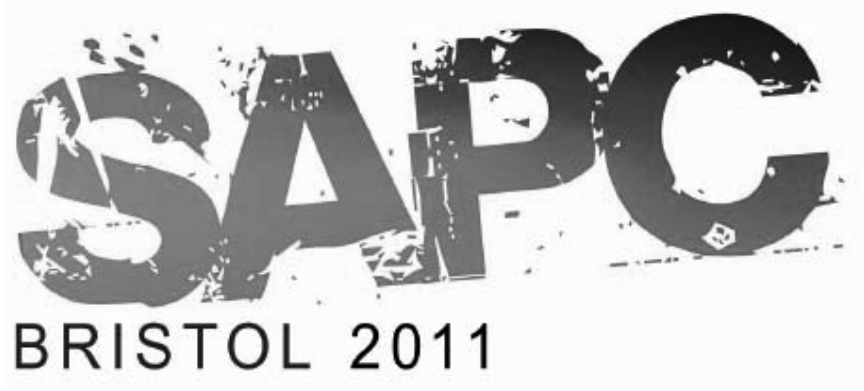

6-8 July, 2011

Wills Memorial Building, University of Bristol

\section{ANNUAL SCIENTIFIC MEETING OF THE SOCIETY OF ACADEMIC PRIMARY CARE}

Everyone who wants to hear about and discuss the latest developments in primary care research and education is very welcome to attend.

For further information: www.sapc.ac.uk/2011 or email Sue Stewart office@sapc.ac.uk

SAPC Bristol 2011 is hosted by the Academic Unit of Primary Health Care, University of Bristol. Conference Chair: Prof Chris Salisbury 


\section{healthlifteracy}

\section{Health Literacy: A Public Health concern?}

\section{1-day Conference at Chancellors Hotel and Conference Centre (Manchester)}

Friday $10^{\text {th }}$ June 2011

\section{Join us for our first national Health Literacy Research Conference.}

The conference will include 2 plenary sessions with international health literacy keynote speakers and a panel discussion.

Cost: $£ 50$ per day

For more information, directions and a booking form: visit our website (Jan 2011) www.healthliteracy.org.uk: or email Lucy on mcdonall@Isbu.ac.uk 


\title{
www.sapc.ac.uk \\ The Society for Academic Primary Care
}

Visit our website to find out about...

- Who we are

- What we do

- How to join us

...and out current hot topics:

\author{
our new \\ POSITION STATEMENT
}

\section{SAPC \\ Special Interest Groups}
ANNUAL SCIENTIFIC MEETING Bristol - July 2011

